\title{
Managing Class II Malocclusion Using Twin Block Therapy in a Young Adolescent Female: A Case Report
}

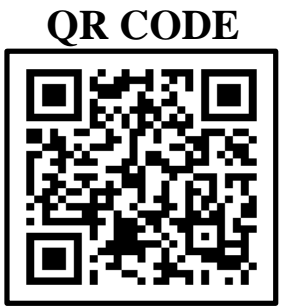

\section{AMAN DEEP'ID, DIPTI CHAWLA*}

Twin block therapy is highly effective in patients with remaining growth potential. However, its successful use is confounded by many patient related factors such as age, gender, compliance of the patient and other miscellaneous criteria's. If treated within time, growth modification and orthopedics can harness suitable forces to cause skeletal correction of the malocclusion. The appliance is highly successful in a patient with retruded mandible and presenting with a positive visual treatment objective. This paper discusses a case of 11-year-old female patient with characteristic twin block appliance indication in which successful skeletal modification was achieved.

KEYWORDS: Malocclusion, Myofunctional Therapy, Adolescent

\section{INTRODUCTION}

Class II Malocclusion is the most frequently encountered skeletal problem in orthodontics which is characterized by deficient mandibular growth. A myriad of studies depicting numerous methods for treatment of such skeletal problem can be seen. However, with some portion of residual growth in hand along with treatment timing and growth vector the most favored treatment modality seems to be growth modulation. There are many removable functional appliances available, however, "the Standard Twin Block appliance" is the treatment modality most favored by the clinicians and patients due to its ease of use and easy maintenance. ${ }^{1-5}$ The appliance was invented by Clark ${ }^{6}$ in 1982 and consisted of removable plates with acrylic blocks for maxillary and mandibular arches. These two blocks were made to engage each other at an angle of $70^{\circ}$. And here lies the point of differentiation between this appliance and other removable functional appliances, which are basically Monoblock's. This appearance of appliance along with less bulky build makes it more comfortable and acceptable to the patients. Additionally, it also provides more freedom in their mandibular movements. ${ }^{7}$

All these considerations eventually produce different treatment results compared with the removable functional monoblock. The following case report illustrates the use of a standard twin block appliance for skeletal correction of a Class II division 1 malocclusion in an 11-year-old female patient.

\section{CASEREPORT}

An 11-year-old girl reported to the department with the chief complaint that her upper front teeth were quite forwardly placed and she had a non-pleasing smile. On extra oral examination, patient had an apparently symmetrical face with a convex facial profile, the lips were competent and mento-labial sulcus was deep with receded chin. Intraoral examination showed an Angle's Class II molar relation and Class II Canine relation. Patient had an overjet of $9 \mathrm{~mm}$ and an overbite of $90 \%$ with coincident midlines (figure 1). Orthopantomogram findings revealed a late transition stage with retained lower second primary molars. [figure 2(a)].

Cephalometric analysis [figure 2(b)] depicted Class II division 1 with a skeletal Class II base and mandibular deficiency. The ANB angle was $6^{\circ}$ [figure 3(a)]. Skeletal values depicted that maxilla was normally positioned, however there was a retruded mandible in relation to cranium and a normodivergent growth pattern as confirmed by Frankfurt-mandibular plane angle as $25^{\circ}$ [figure 3(b)]. Dento-alveolar findings depicted proclined maxillary anterior teeth and mandibular incisors as normally positioned. [figure 3(c)] Cephalogram indicated that she was reaching peak of her pubertal growth spurt (CVMI-III) with considerable growth remaining. Positive visual treatment objective (VTO) showed favorable results of mandibular advancement. 


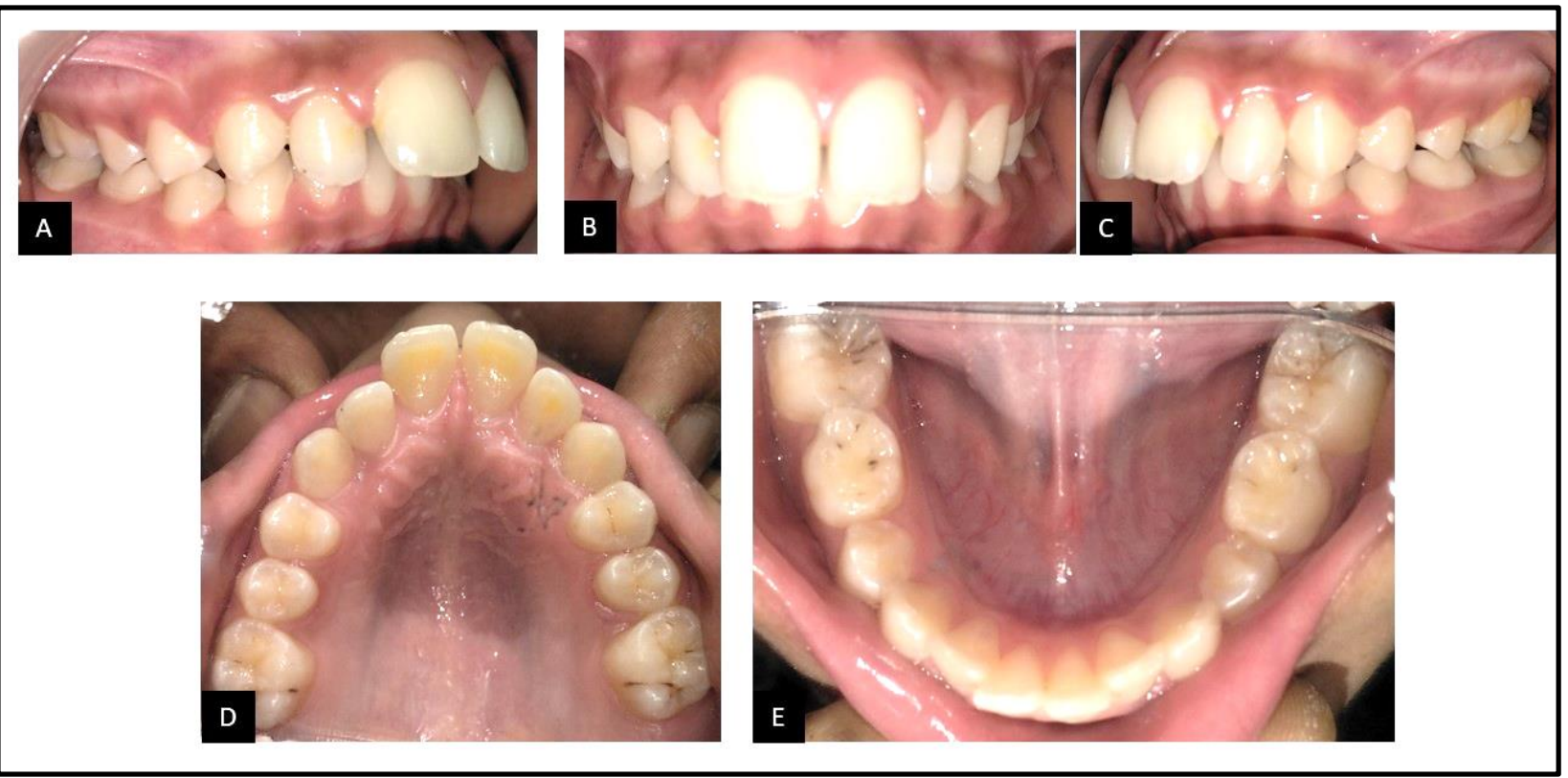

Figure 1. Pre-treatment Intra Oral Photographs

\section{TREATMENT OBJECTIVE}

a. Achieving Angle's Class I molar and canine relationship.

b. Normal over jet and overbite.

c. Levelling and alignment of both the arches.

d. Retention of results for long term.

\section{TREATMENT PLAN}

As the patient was in her growing period with both skeletal and dental class II relation, a two-phase treatment had to be undertaken;

Phase I: Growth modification using functional appliance (twin block).

Phase II: Fixed mechanotherapy for detailing of occlusion.

\section{TREATMENT PROGRESS}

A wax bite registration was done with mandibular arch guided forwardly and twin block appliance was fabricated (figure 4). A 24 hours per day appliance wear was educated to the patient, where periodic recall was done every 1 month, besides this, slight dentoalveolar expansion was done where patient was instructed to

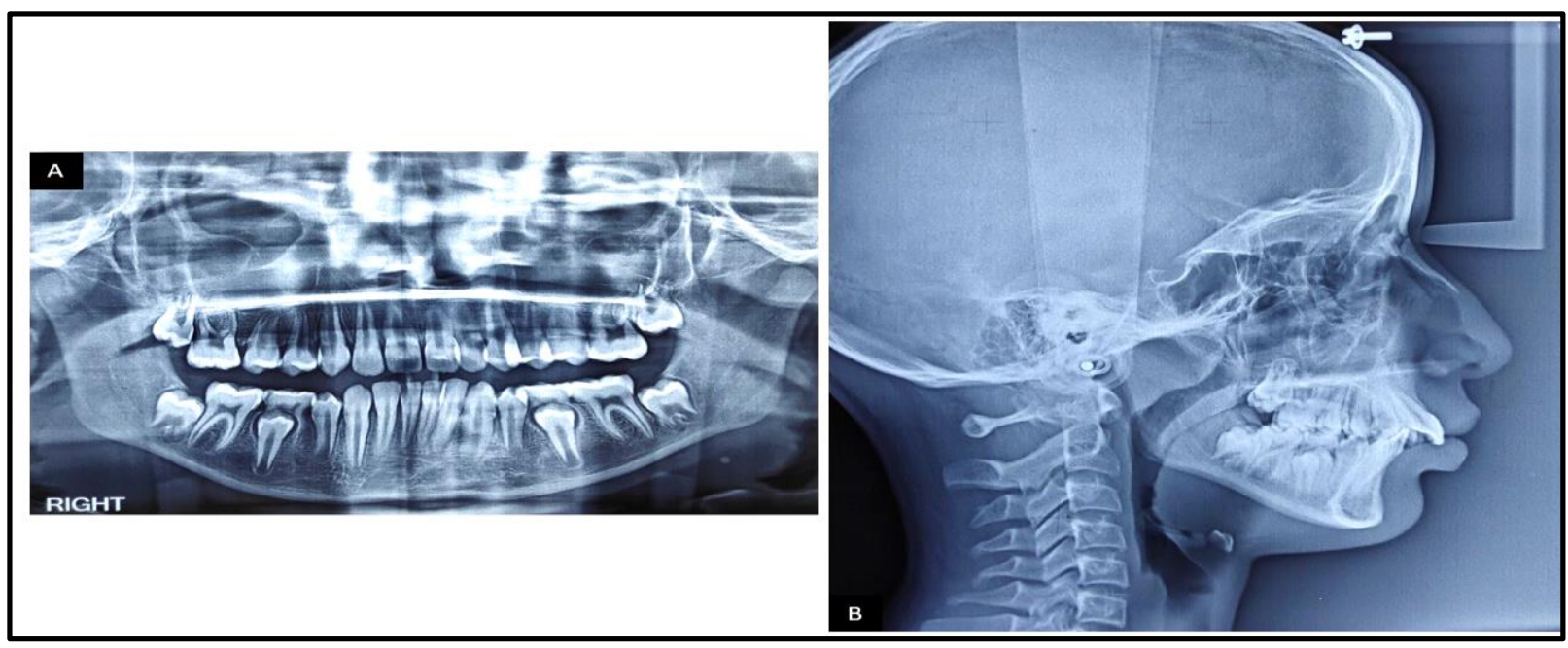

Figure 2(a). Pre-treatment OPG \& 2(b). Pre-treatment Cephalogram 


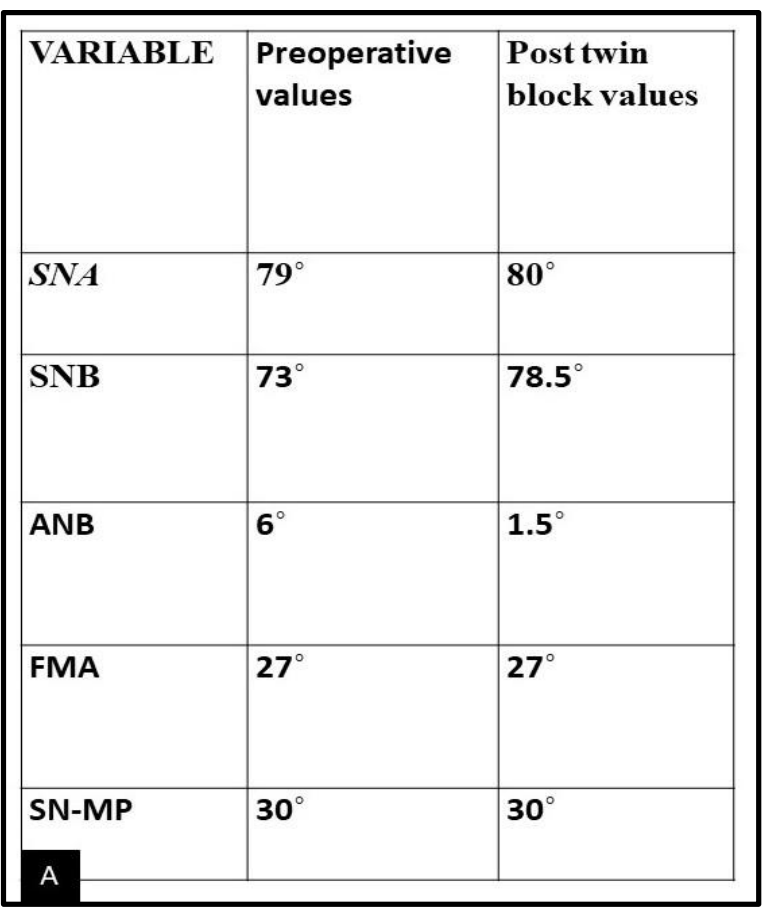

Figure 3(a). Cephalometric parameters of Skeletal Base

rotate the screw quarter turn once a week and following this patient was revaluated after 6 months. The profile of the patient had significantly improved with marked reduction in overjet and overbite. Correction of molar and canine relation had also occurred. This correction was to be followed by

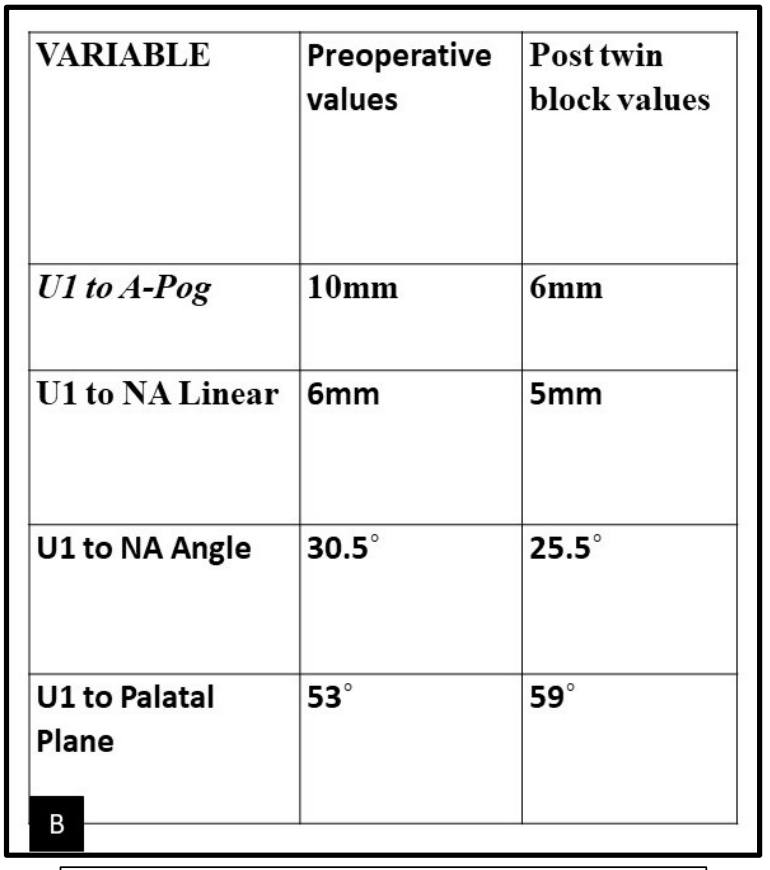

Figure 3 (b). Cephalometric parameters of Growth Pattern

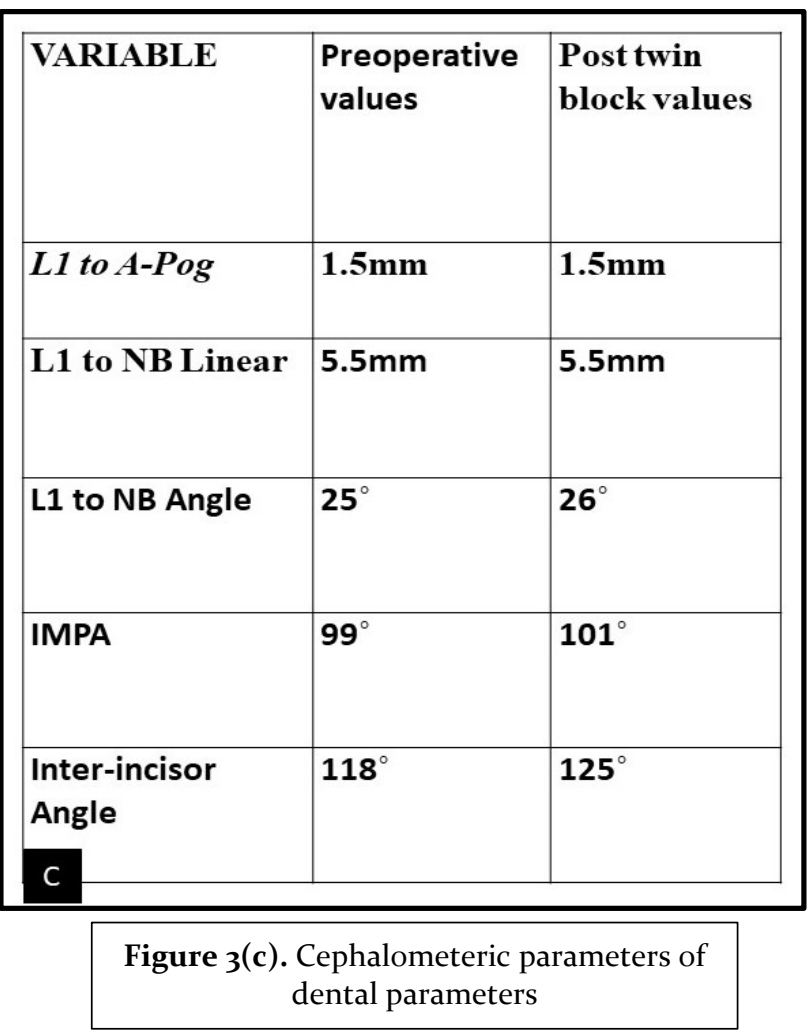

retentive phase where the patient was instructed to wear a removable reverse inclined plane appliance which engaged the lower anterior teeth and retained the correction obtained (figure $5 \& 6$ ).

\section{DISCUSSION}

Class II malocclusion is often associated with skeletal component or a dental component, while it is also true that sometimes both of them could be present. Presence of skeletal component may result in any of the following ways: maxillary prognathism, mandibular retrognathism or their combination. ${ }^{8}$ Therefore, identification of the etiology is extremely important for a true diagnosis and finally to device an effective treatment plan.

This functional appliance are built on the notion that they harnesses the adjacent neuromuscular forces so that orthopedic and orthodontic changes can be brought, which thereby causes mandibular displacement. The main advantage is that changes occur at rapid rate, and its comfortable nature to the patient and long-time wear allows this process to culminate. ${ }^{9}$ A lot of documentation ${ }^{10}$ has been undertaken to gauge the ability of this appliance to produce significant skeletal as well as dentoalveolar changes, where a generalized notion was in favour of the appliance. In this particular case, comparison of 


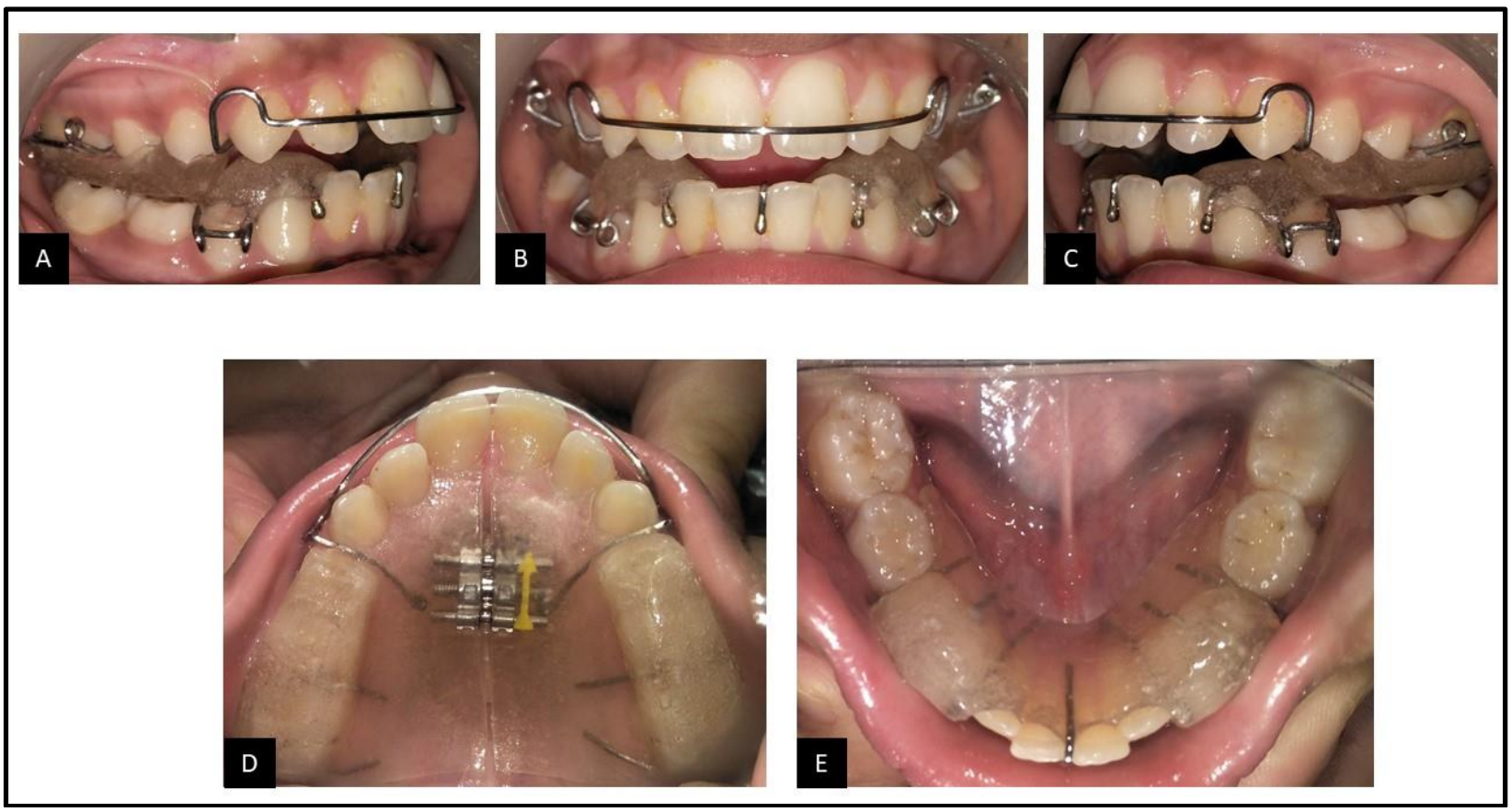

Figure 4. Intraoral photographs of appliance in vivo

pre-treatment and post-twin block treatment lateral cephalogram depicted an increase in SNB angle by $5.5^{\circ}$, while the ANB angle was reduced up to $4.5^{\circ}$. Maxillary incisor inclination was also corrected.

\section{CONCLUSION}

Functional appliance therapy is highly effective in treating skeletal Class II malocclusion with some residual growth potential; however, its use is largely confounded by patient compliance and case selection factors. Eventually, they help in simplifying the following phase of fixed appliance by gaining anchorage and achieving Class I molar relationship.

\section{REFERENCES}

1. Bonde PV, Kerudi VV, Patil N, Dolas S G, Patil H A. Treatment of Skeletal Class II Malocclusion with Twinblock. JOADMS 2015;1(3):57-61.

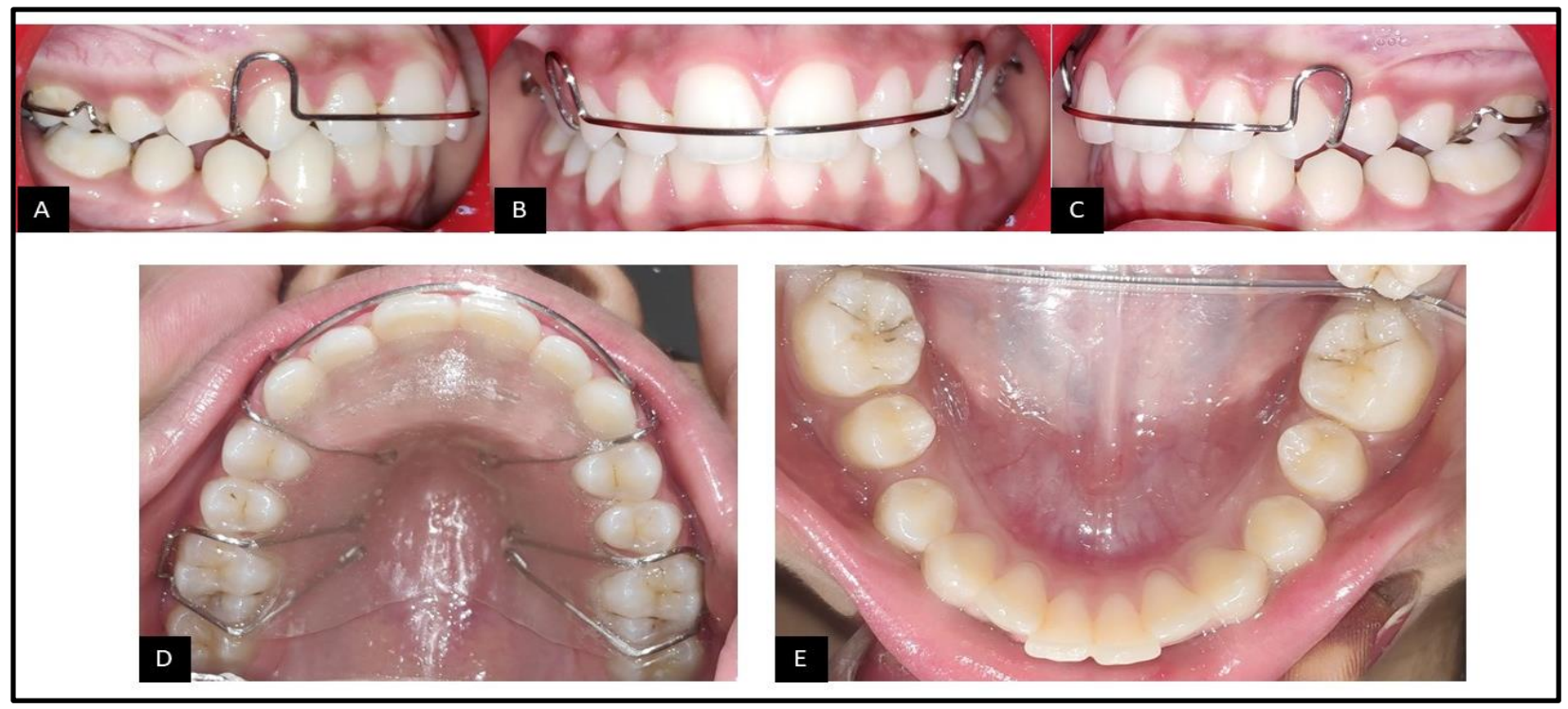

Figure 5. Intraoral photographs of appliance during retention phase 


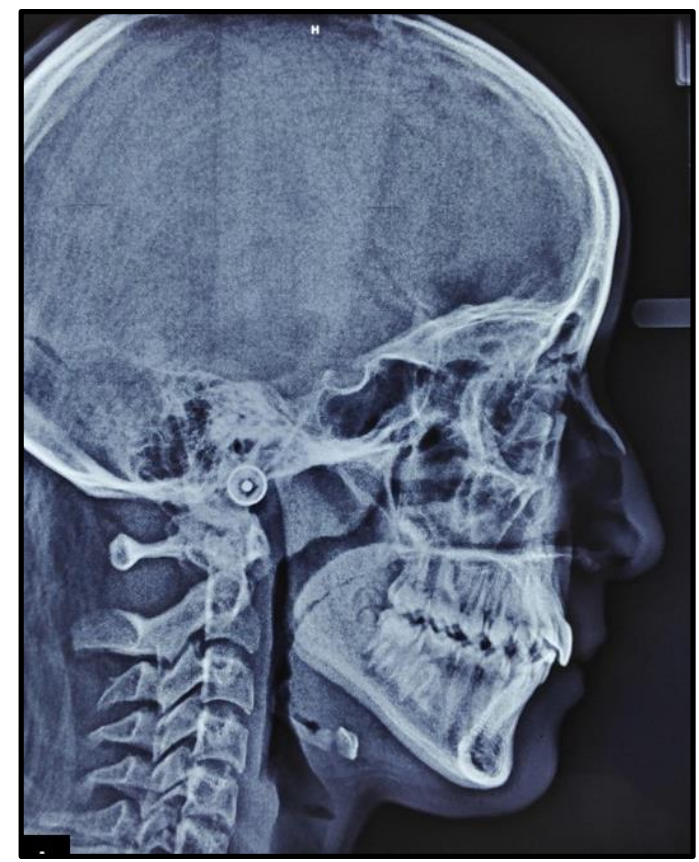

Figure 6. Posttreatment cephalogram

2. Proffit WR, Fields HW, Moray LJ. Prevalence of malocclusion and orthodontic treatment need in the United States: estimates from the NHANES III survey. Int J Adult Orthodon Orthognath Surg. 1998;13(2):97106.

3. Gelgor IE, Karaman AI, Ercan E. Prevalence of malocclusion among adolescents in central Anatolia. Eur J Dent. 2007;1(3):125-31.
4. Celikoglu M, Akpinar S, Yavuz I. The pattern of malocclusion in a sample of orthodontic patients from Turkey. Med Oral Patol Oral Cir Bucal. 2010;15(5): e7916. https://doi.org/10.4317/medoral.15.e791. 5. McNamara JA. Components of Class II malocclusion in children 8-10 years of age. Angle Orthod. 1981;51(3): 177-202. https://doi.org/10.1043/00033219(1981)051<0177:COCIMI>2.0.CO;2

6. Clark WJ. The Twin Block technique. A functional orthopaedic appliance system. Am J Orthod Dentofac Orthop. 1988;93(1): 1-18. https://doi.org/10.1016/o8895406(88)90188-6.

7. Mills JR. The effect of functional appliances on the skeletal pattern. $\mathrm{Br}$ J Orthod. 1991;18(4): 267-75. https://doi.org/10.1179/bjo.18.4.267

8. Arici S, Akan H, Yakubov K, Arici N. Effects of fixed functional appliance treatment on the temporomandibular joint. Am J Orthod Dentofacial Orthop. 2008;133(6):809-14. https://doi.org/10.1016/j.ajodo.2006.07.035.

9. O'Brien K, Wright J, Conboy F, Sanjie Y, W.Mandall $\mathrm{N}$, Chadwich S, et al. Effectiveness of treatment for Class II malocclusion with the Herbst or Twin-block appliances: a randomized, controlled trial. Am J Orthod Dentofacial Orthop. 2003; 124: 128-37. https://doi.org/10.1016/so889-5406(03)oo345-7.

10. Mezio M, Giovannoni D, Caterini L, Dari M, Pacella E. Twin Block appliance. A Systematic Review. Webmed Central Orthodontics 2017;8(11):WMCo05372

Cite this article as:

Deep A, Chawla D. Managing Class II Malocclusion Using Twin Block Therapy in a Young Adolescent Female: A Case Report. Int Healthc Res J. 2021;5(3):CR1-CR5. https://doi.org/10.26440/IHRJ/0503.06407

AUTHOR AFFILIATIONS: (*Corresponding Author)

1. MDS, Senior Resident, Department of Pedodontics and Preventive Dentistry (https://orcid.org/oooo-0002-3486-1963)

2. Junior Resident, Department of Orthodontics and Dentofacial Orthopedics

Bhojia Dental College and Hospital, Baddi Solan, H.P. 